\title{
Application of response surface methodology (RSM) for optimization of color removal from POME by granular activated carbon
}

\author{
M. F. Alkhatib · A. A. Mamun · I. Akbar
}

Received: 24 October 2013/Revised: 13 December 2013/Accepted: 11 January 2014/Published online: 6 February 2014

(C) Islamic Azad University (IAU) 2014

\begin{abstract}
Color is one of the major remaining contaminants in the palm oil mill effluent (POME) following the conventional treatment of POME. The removal of color from POME using adsorption on activated carbon was investigated. The adsorption experimental design was performed using the standard response surface method (RSM) design that is central composite design to determine the optimum process variables for color removal by using the Design-Expert software (version 7.0. Stat-Ease, trial version). Besides obtaining optimum values, RSM also has the advantage of studying the interaction between various experimental parameters compared to one-factor-at-a-time. The equilibrium experimental data were analyzed by Langmuir and Freundlich isotherms. The statistical analysis showed that the quadratic model as well as the model terms was significant. The model had very low probability value $(0.0003)$. The $R^{2}$ for the model was 0.9184 and the adjusted $R^{2}$ was 0.8380 . The validation of the model showed experimental value and predicted value of 0.124 and 0.106 , respectively. The optimum conditions suggested by the model for the process variable were $87.9 \mathrm{~min}, 4.05$ and $7.86 \mathrm{~g}$, for time, $\mathrm{pH}$ and granular activated carbon dose, respectively. The maximum removal obtained at these conditions was $89.95 \%$. The adsorption isotherm data were fitted well to the Langmuir isotherm compared to Freundlich isotherm with $R^{2}$ value of 0.850 for the former and 0.273 for the later.
\end{abstract}

M. F. Alkhatib ( $\square)$ · A. A. Mamun · I. Akbar Nanoscience and Nanotechnology Research Group (NANORG), Department of Biotechnology Engineering, Faculty of Engineering, International Islamic University Malaysia, P.O. Box 10, 50728 Kuala Lumpur, Malaysia e-mail: maan@iium.edu.my
Keywords Activated carbon - Adsorption - Palm oil mill effluent · Color · Central composite design - Response surface method

\section{Introduction}

Malaysia is one of the world's leading producers and exporters of Palm oil which is an expanding agro-industrial sector to meet world's demands (Yusoff 2006). Palm oil mill effluent (POME) is the most significant source of pollutants discharged from palm oil mills. Serious environmental pollution could result from direct discharge of POME into the environment (Bello et al. 2013). It is estimated that for 1 ton of crude palm oil produced, 5-7.5 tons of water are required, and more than $50 \%$ of the water ends up as POME (Ahmad et al. 2003). Raw POME is a thick brownish colloidal suspension containing 95-96\% water, $0.6-0.7 \%$ oil and $4-5 \%$ total solids including 2-4\% suspended solids that mainly consist of debris from palm fruit mesocarp generated from three main sources, namely sterilizer condensate, separator sludge and hydrocyclone wastewater (Borja and Banks 1994). The current typical treatment technology of POME consists of biological digestion which is a combination of aerobic and anaerobic ponds. Yet, color remains as one of the constituents of the discharged effluent, which require removal from environmental and esthetic point of view (Zahrim et al. 2009). POME due to its color does not only degrade the esthetic value of the water bodies but also interfere with the penetration of light into the water, thereby leading to disturbances in the aquatic ecosystem (Mittal et al. 2010).

There are many processes available for removal of color from waste effluents, namely chemical oxidation (McClung and Lemley 1994), foam flotation (Lin and Lo 1996), 
electrolysis (Bousher et al. 1997), biodegradation (Oakes and Gratton 1998), adsorption (Poulios and Aetopoulou 1999; Ncibi et al. 2007), chemical coagulation (Papic et al. 2000) and photocatalysis (Lopez-Grimau and Gutierrez 2006; Divya et al. 2013). However, adsorption onto activated carbon seems to be one of the effective and reliable physicochemical treatment methods (Pala and Tokat 2002; Mall et al. 2005) and due to economical and environmentally friendly reasons (Toor and Jin 2012).

Adsorption has been considered as the best wastewater treatment method due to its universality, inexpensiveness and operational simplicity. Water treatment costs of other methods previously highlighted could range from 10 to 450 USD per cubic meter besides their operational sophistication, whereas adsorption cost in water treatment could be as low as 5.0-200 USD per cubic meter. Adsorption process is not only cheap but cost-efficient as well, as the removal capacities of these adsorbents could be as high as $99.9 \%$ (Ali et al. 2012; Ali 2013).

Adsorption processes could still be cheaper than expected when the precursors utilized in adsorbent's production are of very cheap and readily available types. Commercially available activated carbon has long been used as a standard adsorbent for color removal which still makes activated carbon expensive despite its universal use. The development of low-cost activated carbon especially from wastes has been the focus of various researches (Gupta et al. 2007).

Gupta et al. (2006) reported the efficient removal of the complex Brilliant Blue FCF dye from water; this is an indication that adsorption using low-cost, non-toxic and readily available adsorbents can stand up to scrutiny besides others but limited decolorization techniques. Velmurugan et al. (2011) also reported similar findings on the use of alternative low-cost adsorbent for the removal of Methylene blue.

As observed from previous studies (Karthikeyan et al. 2012), experimental design and optimization using CCD under response surface method (RSM) is one of the most efficient and accurate means to experimentally investigate and evaluate the best effects of necessary operating conditions in utilizing activated carbon for wastewater treatment. Therefore, this research aimed to study the capability of granular activated carbon for residual color removal from treated POME. The effects of operating parameters such as initial $\mathrm{pH}$, time $(\mathrm{min})$ and GAC dose $(\mathrm{g})$ on the adsorption of color on activated carbon were analyzed using RSM. The adsorption isotherms were determined and fitted to Langmuir and Freundlich isotherms. This research was conducted between March 2012 and May 2013 at environmental engineering laboratory, biotechnology engineering department, International Islamic University Malaysia.

\section{Materials and methods}

Preparation of GAC

The GAC, palm kernel based, obtained from KD Technology Sdn Bhd, Malaysia, was repeatedly washed with distilled water to remove any kind of impurity in the particles. The washing continued until the $\mathrm{pH}$ of water was rendered neutral and the water became colorless. Then, the washed GAC was placed in a preset oven at $105^{\circ} \mathrm{C}$ for $1 \mathrm{~h}$ to remove the moisture. The GAC was then placed in a desiccator to cool down. The samples were stored in Falcon tubes, with covers closed tightly, for further use.

Preparation of the POME stock solution

The POME was collected from a local industry and was kept at $4{ }^{\circ} \mathrm{C}$ temperature to prevent any changes on its characteristics. Prior to experimental use, POME was filtered. The filtrate was then diluted to predetermined color concentrations to set as a stock solution which was used for further adsorption experiments.

\section{Analytical methods}

The initial color of the solution was determined using the spectrophotometer (HACH, model DR-5000) by measuring its absorbance and estimating the highest absorbance value. For the original stock sample, $600 \mathrm{~nm}$ wavelength gave the maximum absorbance of 0.299 . Hence, it was set as the initial POME color concentration $\left(C_{\mathrm{o}}\right)$.

The percentage removal of color was calculated using Eq. 1:

Percentage removal $(\%)=\frac{\left(C_{\mathrm{o}}-C_{\mathrm{f}}\right)}{C_{\mathrm{o}}} \times 100$

where, $C_{\mathrm{o}}=$ initial concentration of color in POME; $C_{\mathrm{f}}=$ final concentration of color in POME.

Optimization of adsorption experiment

Adsorption experiments were conducted in batch mode at room temperature $\left(27^{\circ} \mathrm{C}\right)$, a $\mathrm{pH}$ range of $4-8$, contact time (15-120 min) and GAC doses (1-10 g/50 $\mathrm{ml}$ of the sample volume). A series of conical flasks containing $50 \mathrm{ml}$ of the POME sample with the desired dose of the adsorbent were set in the incubator at an agitation speed of $150 \mathrm{rpm}$.

Optimization experiments were designed using the most popular RSM design which is the central composite design (CCD). It is well suited for fitting a quadratic surface and usually works well for the process optimization. The CCD allows a reasonable amount of information for testing lack of fit while not involving an unusually large number of 
Table 1 Experimental design of color adsorption on GAC

\begin{tabular}{lcc}
\hline Independent variable & Low actual value & High actual value \\
\hline pH & 4 & 8 \\
Time (min) & 15 & 120 \\
GAC dose (g) & 1 & 10 \\
\hline
\end{tabular}

design points (Özer et al. 2009). Therefore, face centered composite design (FCCD) with three factors was applied using Design-Expert ${ }^{\circledR}$ 7.0. The experimental design of color adsorption on GAC is shown in Table 1. At the end of each run of $\mathrm{CCD}$, the sample was vacuum filtered using $0.2-\mu \mathrm{m}$ membrane filter, and the color residual concentration was measured $\left(C_{\mathrm{f}}\right)$.

Adsorption isotherms and adsorption capacity

Palm oil mill effluent was prepared at different dilution rates and then subjected to a GAC dose of $0.15 \mathrm{~g} / \mathrm{ml}$ of POME, $\mathrm{pH}$ of 4.0 and $150 \mathrm{rpm}$ agitation speed. The samples were then set in the shaker for fixed time periods; 5, $10,15,30,45,60,75,90,105$ and $120 \mathrm{~min}$.

The adsorption capacity of GAC was then determined by Eq. 2 :

$\operatorname{Adsorption}$ capacity $(\mathrm{g} / \mathrm{g})=\frac{\left(C_{\mathrm{i}}-C_{\mathrm{e}}\right) \times V}{M}$

where $C_{\mathrm{i}}=$ initial concentration of color (absorbance); $C_{\mathrm{e}}=$ equilibrium concentration of color (absorbance); $V=$ volume of the POME solution $(20 \mathrm{ml}) ; M=$ weight of the GACs (3 grams).

The two well-known adsorption models, namely Langmuir and Freundlich adsorption isotherms were used to model the experimental data from color adsorption onto GACs.

The Langmuir adsorption isotherm is expressed in Eq. 3:

$\frac{C_{\mathrm{e}}}{Q_{\mathrm{e}}}=\frac{1}{q_{\mathrm{m}} K_{\mathrm{L}}}+\frac{C}{q_{\mathrm{m}}}$

where $Q_{\mathrm{e}}=$ the adsorption capacity at the equilibrium solute concentration $C_{\mathrm{e}} ; q_{\mathrm{m}}=$ Langmuir constant related to the adsorption capacity; $K_{\mathrm{L}}=$ Langmuir constant related to energy of adsorption; $C_{\mathrm{e}}=$ the concentration of color in solution $(\mathrm{mg} / \mathrm{l})$.

The Langmuir constants $q_{\mathrm{m}}$ and $K_{\mathrm{L}}$ were evaluated from the slope and intercept of the linear equation.

The Freundlich adsorption isotherm is expressed in its linear from in Eq. 4.

$\log Q_{\mathrm{e}}=\frac{1}{n} \log C_{\mathrm{e}}+\log K_{\mathrm{F}}$

where $Q_{\mathrm{e}}=$ adsorption capacity of GACs at equilibrium $(\mathrm{g} / \mathrm{g}) ; C_{\mathrm{e}}=$ equilibrium concentration of color; $K_{\mathrm{F}}=$
Freundlich constant related to the adsorption capacity; $n=$ Freundlich constant related to the adsorption intensity.

The adsorption isotherm describes how adsorbates interact with adsorbents, and therefore, it is critical in optimizing the use of adsorbents.

\section{Results and discussion}

\section{Effect of $\mathrm{pH}$}

It is factual that one of the most important factors driving adsorption efficacy is the $\mathrm{pH}$; however, there are certain limits at which the $\mathrm{pH}$ could be altered due to the unfavorable effects (such as corrosive attack on vessels/reactors and additional cost for the acidic additives) of too low $\mathrm{pH}$ especially when considering the up scaling of experiments. It is thereby deemed fit to balance the compromise between the adsorbent's effectiveness and lowering of $\mathrm{pH}$; hence, these findings were done within acceptable $\mathrm{pH}$ ranges of $4-8$ which is between relatively not highly acidic and less alkaline. The time and GAC concentration were fixed at $67.5 \mathrm{~min}$ and $5.5 \mathrm{~g}$, respectively. It is observed in Fig. 1 that as the $\mathrm{pH}$ increased, color removal decreased. The removal dropped from $85 \%$ at $\mathrm{pH} 4$ to $52 \%$ at $\mathrm{pH} 8$. Color in POME is a result of the presence of organic materials such as lignin, phenolics, pectin and carotene, which easily form negatively charged ions in aqueous state (Bello et al. 2013). Therefore, the low removal of color at high $\mathrm{pH}$ could be explained by electrostatic repulsion with the negatively charged carbon surface. At low $\mathrm{pH}$, most carbons are positively charged, at least in part as a consequence of donor/acceptor interactions between the graphene layers and the hydronium ions (Leon y Leon et al. 1992). This enhances the electrostatic attraction between the positively charged carbon and the anions in the solution. The results indicated the importance of $\mathrm{pH}$ as a parameter affecting the adsorption process due to its effect on the adsorbent surface charge. The results are in

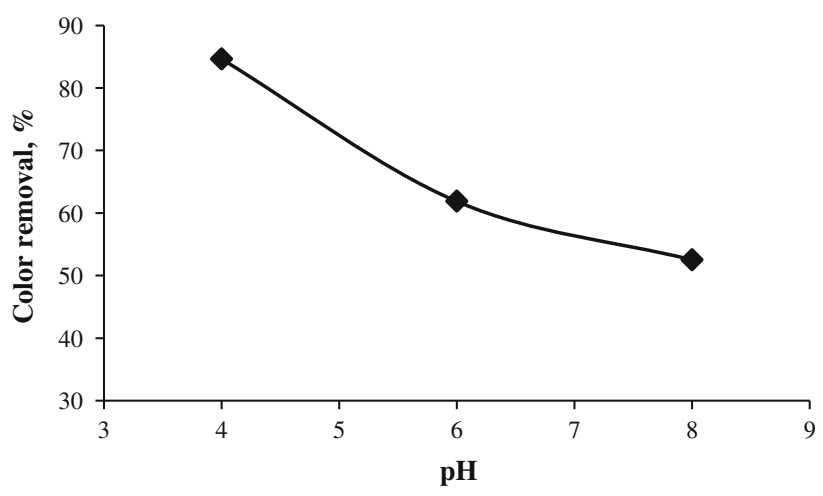

Fig. 1 Effect of $\mathrm{pH}$ on POME color removal 


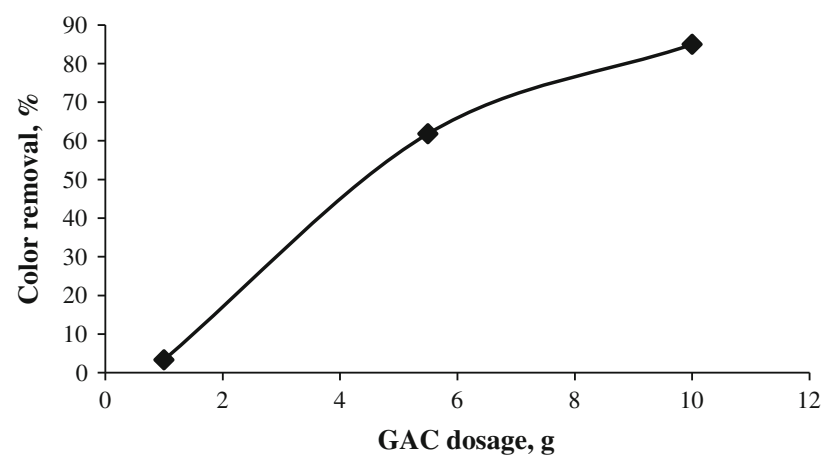

Fig. 2 Effect of GAC dose on POME color removal

agreement with the findings of Mohammed (2013). He studied the effect of $\mathrm{pH}$ from 2 to 12 on color removal from POME by adsorption. Increasing $\mathrm{pH}$ value from 2.0 to 8.4 was observed to diminish the adsorption capacity, whereas the successive increase in $\mathrm{pH}$ value up to 12 no longer had a significant effect on the adsorption capacity. Gupta et al. (2009) and Baseri et al. (2012) presented comparable results on dye removal by activated carbon adsorption. Similar findings were reported by Gupta et al. (2011) on chromium removal that there was a limit ( $\mathrm{pH} \mathrm{5)}$ at which the $\mathrm{pH}$ could be increased to get maximum removal efficiency. Mittal et al. (2008) evaluated the effect of $\mathrm{pH}$ range from 1 to 10 in the uptake of azo dye by adsorption and found out that there was a drastic reduction in the amount of dye adsorbed as the $\mathrm{pH}$ increased. Same reason as previously given was attributed to the effects of $\mathrm{pH}$. The effect of $\mathrm{pH}$ could also be as a result of the involvement of proton in the adsorption process over the $\mathrm{pH}$ range depicting that as the $\mathrm{pH}$ was gradually increased, the potential or uptake kept on shifting toward less positive values. Observations similar to this were reported by Sanghavi and Srivastava (2010) and Sanghavi et al. (2013).

\section{Effect of GAC dose}

The uptake of color increased with GAC dose as shown in Fig. 2. The dose was varied from 1 to $10 \mathrm{~g}$, while $\mathrm{pH}$ and time were fixed at 6 and $67.5 \mathrm{~min}$, respectively. The higher uptake at greater GAC dose could be explained by the increase in active sites accessible for adsorption. This is an expected pattern, whereby the removal percentage increased with the increase in adsorbent dose. Furthermore, it is noticed from Fig. 2 that the uptake increased $60 \%$ when concentration increased from 2 to $6 \mathrm{~g}$. While the uptake increased by $20 \%$ when dose increased from 6 to $10 \mathrm{~g}$. This could be explained by the fact that adsorption equilibrium has been reached between the adsorbent/ POME, thereby preventing further color removal by the excess adsorbent dose (Mohammed 2013).

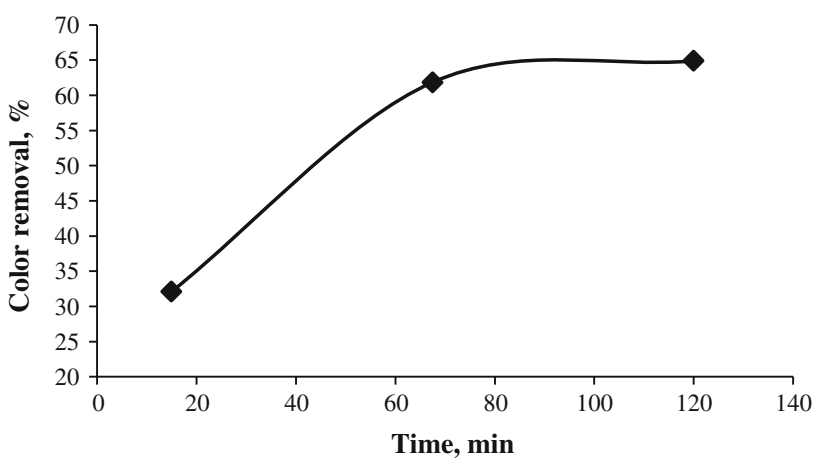

Fig. 3 Effect of contact time on POME color removal

Effect of contact time

The percentage of color removal by GAC increased with contact time as shown in Fig. 3. At lower contact time, GAC pores are fresh and large surface area is available for adsorption. The uptake of color was rapid at the initial period of contact time. Gradually the pores start to be filled with adsorbate until GAC becomes saturated and finally color removal decreased markedly, indicating slower uptake at longer contact time.

\section{Optimization results}

Table 2 refers to the corresponding analysis of variance (ANOVA) for color adsorption capacity with $A$ contact time (min), $B \mathrm{pH}$, and $C$ GAC dose (g). The Model $F$ value of 11.92 implies the model is significant. Values of "Prob $>F$ " less than 0.05 indicate model terms are significant. In this case, $A, B, C$ and $B C$ are significant model terms.

The model equation indicates that the high $R^{2}$ of 0.9148 showed that $91.48 \%$ of the variations in adsorption capacity can be explained by the independent variables: contact time, $\mathrm{pH}$ and GAC dose. The model also showed that $R^{2}$ is in reasonable agreement with adjusted $R^{2}$ value of 0.8380 for color removal. The closer the $R^{2}$ value to unity, the better the model. This implies that the theoretical values will be closer to the experimental values for the response. According to these criteria, the best model can therefore be identified.

The regression model for color removal (\%) in terms of the factors to be optimized is developed in Eq. 5:

$$
\begin{aligned}
\text { Removal }= & 60.49+11.8^{*} A-11.74^{*} B+26.25^{*} C \\
& -8.40^{*} A^{*} B-5.56^{*} A^{*} C+12.92^{*} B^{*} C \\
& -9.95^{*} A 2+10.12^{*} B 2-14.30^{*} C 2
\end{aligned}
$$

The coefficients with one factor represent the effect of the particular factor, while the coefficients with two factors 
Table 2 ANOVA for response surface quadratic model

\begin{tabular}{|c|c|c|c|c|c|c|}
\hline Source & Sum of squares & $d f$ & Mean square & $F$ value & $\begin{array}{l}p \text { value } \\
\text { Prob }>F\end{array}$ & \\
\hline Model & $13,222.96$ & 9 & $1,469.22$ & 11.92 & 0.0003 & Significan \\
\hline$A$-time & $1,393.807$ & 1 & $1,393.81$ & 11.31 & 0.0072 & \\
\hline$B$-pH & $1,378.088$ & 1 & $1,378.09$ & 11.18 & 0.0074 & \\
\hline$C$-GAC dose & $6,892.768$ & 1 & $6,892.77$ & 55.94 & $<0.0001$ & \\
\hline$A B$ & 564.8949 & 1 & 564.89 & 4.58 & 0.0579 & \\
\hline$A C$ & 247.3322 & 1 & 247.33 & 2.01 & 0.1869 & \\
\hline$B C$ & $1,334.993$ & 1 & $1,334.99$ & 10.83 & 0.0081 & \\
\hline$A^{2}$ & 272.3437 & 1 & 272.34 & 2.21 & 0.1679 & \\
\hline$B^{2}$ & 281.3816 & 1 & 281.38 & 2.28 & 0.1617 & \\
\hline$C^{2}$ & 562.2875 & 1 & 562.29 & 4.56 & 0.0584 & \\
\hline$R^{2}$ & 0.9148 & & & & & \\
\hline $\operatorname{Adj} R^{2}$ & 0.8380 & & & & & \\
\hline
\end{tabular}

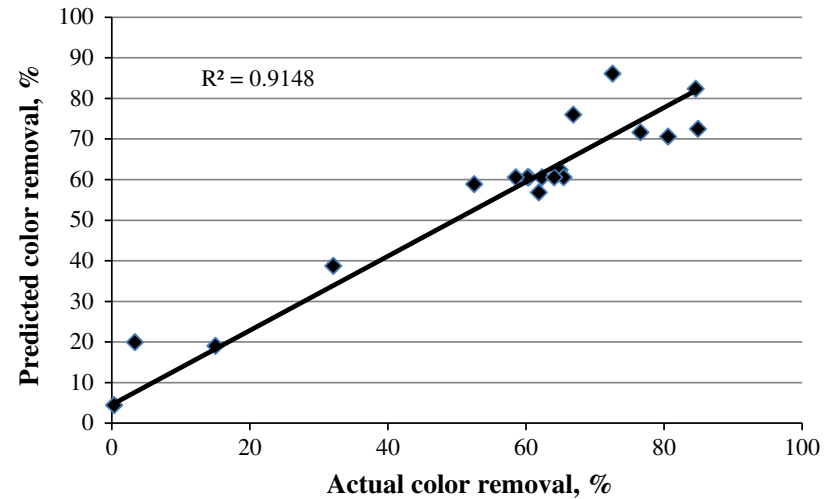

Fig. 4 Experimental versus predicted color removal

Table 3 Experimental validation of the empirical model

\begin{tabular}{lllll}
\hline $\begin{array}{l}\text { Contact time } \\
(\mathrm{min})\end{array}$ & $\mathrm{pH}$ & $\begin{array}{l}\text { GAC } \\
\text { dose }(\mathrm{g})\end{array}$ & $\begin{array}{l}\text { Experimental } \\
\text { removal }(\%)\end{array}$ & $\begin{array}{l}\text { Predicted } \\
\text { removal }(\%)\end{array}$ \\
\hline 67.50 & 6.0 & 5.50 & 0.124 & 0.106 \\
\hline
\end{tabular}

represent the interaction between the two factors. The positive sign in front of the terms indicates a synergistic effect, whereas a negative sign indicates an antagonistic effect (Alkhatib et al. 2011). Hence, as contact time and dose increases, color removal is expected to increase, which is contrary to the effect of $\mathrm{pH}$. This behavior is in agreement with the findings as discussed earlier.

The predicted color removal percentages versus the observed values are shown in Fig. 4. The predicted values are calculated using the empirical model as shown in Eq. 5. It could be observed that the predicted model represents well over wide range of parameters applied.
The optimum conditions which were recommended by Design-Expert software were used to verify the model obtained (Eq. 5). The results are shown in Table 3.

Table 3 shows that the predicted value of color removal percent is in agreement with the experimental value with a minor error.

The response surface plots for color removal percent are shown in Fig. 5. It could be seen from Fig. 5a that color removal was very low at low activated carbon dose and contact time. Color removal increased with both dose and contact time. This is expected as at higher dose, more surface area is available for adsorption and longer times increases the interaction between the active surface and adsorbate allowing more removal to take place. Figure $5 b$ shows the effect of contact time and $\mathrm{pH}$ on color removal. It can be seen that the color removal increased as $\mathrm{pH}$ increased. The increase in removal with $\mathrm{pH}$ is more significant at higher contact time. The interaction between $\mathrm{pH}$ and activated carbon dose is shown in Fig. 5c. It could be observed that although the removal increased with $\mathrm{pH}$, yet the effect of $\mathrm{pH}$ on color removal was more significant at lower doses.

\section{Adsorption isotherms}

Contact time is an important factor influencing the adsorption equilibrium. The color removal change with contact time at different initial concentrations is represented in Fig. 6. It can be seen that contact time of $60 \mathrm{~min}$ was sufficient to achieve equilibrium.

The process was found to be very rapid initially, and a high percentage of color was removed within few minutes. Figure 6 (inset) clearly shows that the removal of color was dependent on its initial concentration (Namasivayam et al. 

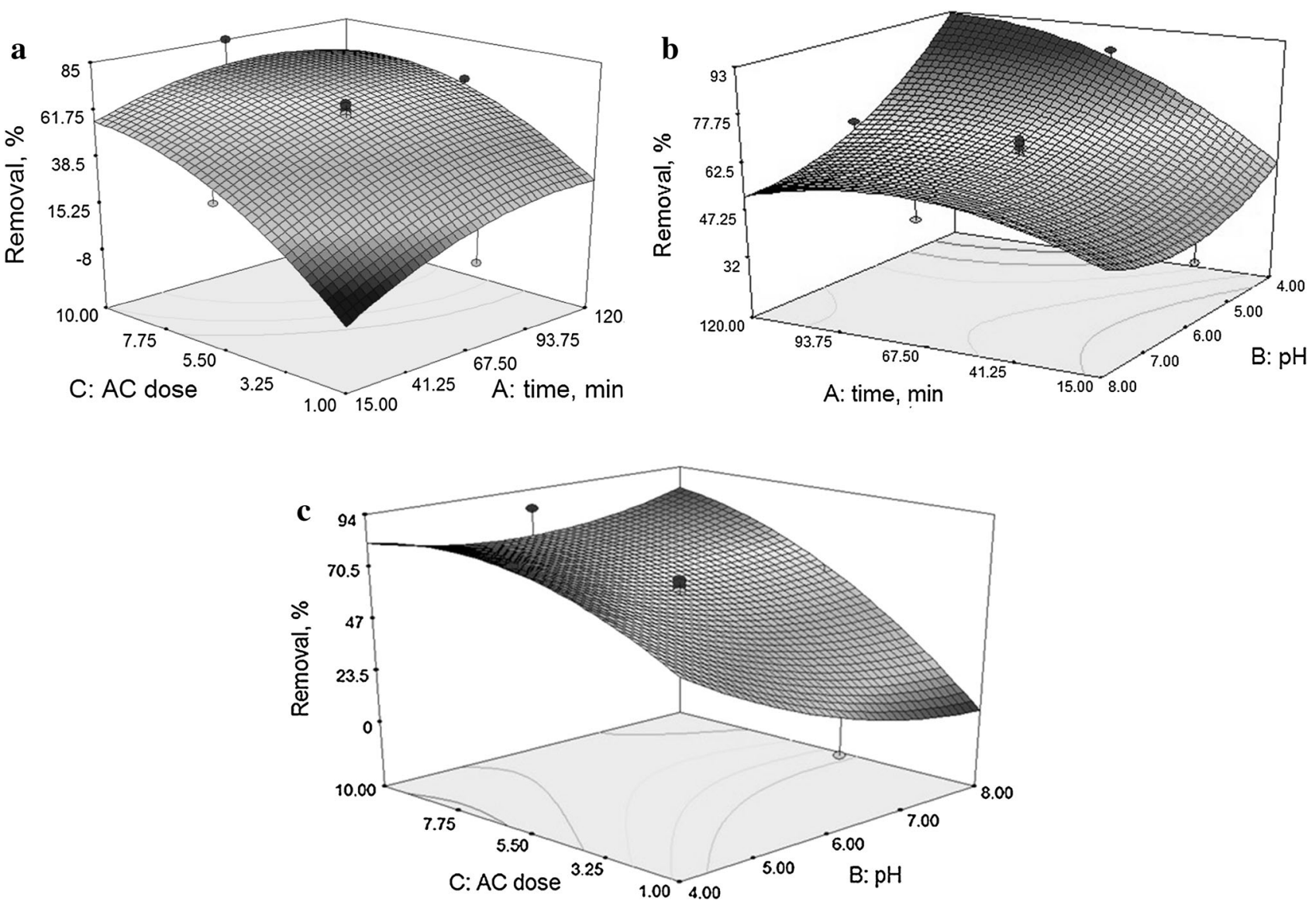

Fig. 5 Color percent removal as a function of $\mathbf{a} A C$ dose and time, $\mathbf{b} \mathrm{pH}$ and time and $\mathbf{c} A C$ dose and $\mathrm{pH}$

Fig. 6 Effect of contact time on color removal at various initial concentrations. Inset effect of initial concentration on color removal

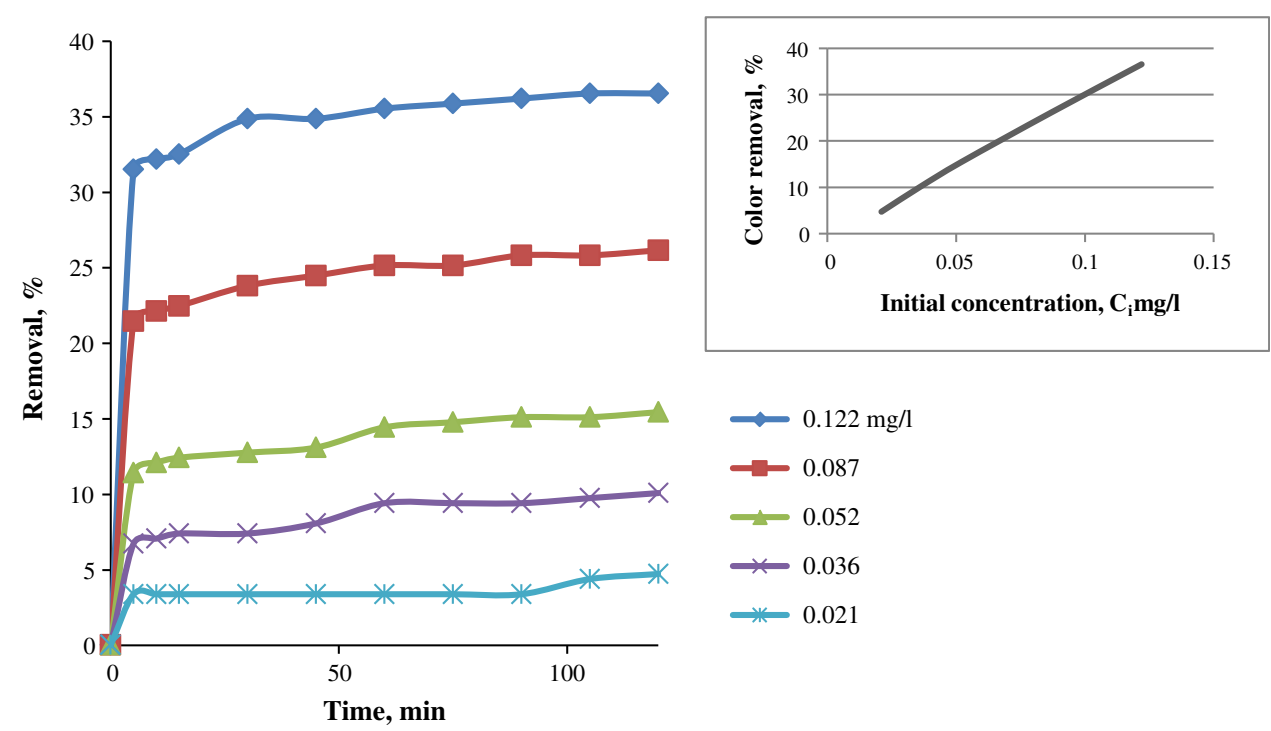

2001a, b). As the initial color concentration increased the removal increased. The increase in adsorption capacity of adsorbent may be due to the higher probability of collision between phenol and adsorbent (Alam et al. 2006).
The Langmuir and Freundlich isotherm models were applied to the experimental data, and using the linear regression method, the isotherm model constants were calculated as shown in Table 4. As can be observed, the 
Table 4 Model constants for Freundlich and Langmuir isotherms

\begin{tabular}{lllllll}
\hline Freundlich & & & & \multicolumn{2}{l}{ Langmuir } \\
\cline { 1 - 1 } \cline { 6 - 7 } & $K_{\mathrm{F}}$ & $R^{2}$ & & $q_{\mathrm{m}}(\mathrm{g} / \mathrm{g})$ & $K_{\mathrm{L}}$ & $R^{2}$ \\
\hline 0.153 & 0.119 & 0.273 & & 0.119 & 37.56 & 0.85 \\
\hline
\end{tabular}

Langmuir isotherm showed a good agreement with the experimental data with $R^{2}$ of 0.85 , while Freundlich showed very low $R^{2}$ of 0.27 . The Freundlich type adsorption isotherm is an indication of surface heterogeneity of the adsorbent, while Langmuir model hints surface homogeneity of the adsorbent (Acar and Eren 2006). $K_{\mathrm{L}}$ $(1 / \mathrm{mg})$ for Langmuir isotherm is a constant related to the affinity of binding sites. Therefore, the high value of $K_{\mathrm{L}}$ implies strong bonding of color on GAC.

\section{Conclusion}

Palm oil mill effluent color removal on GAC was studied using RSM. The removal of color was related to the batch experiment parameters by quadratic model. The model was able to predict the experimental data to high accuracy with $R^{2}$ of 0.9148 . The color removal was highly influenced by $\mathrm{pH}$, contact time and GAC dose. While removal decreased with increase in $\mathrm{pH}$, it showed increase with contact time and GAC dose. The Langmuir and Freundlich isotherm models were applied to the equilibrium data. The study showed that POME color can be removed using GAC, and the adsorption process followed Langmuir isotherm.

Acknowledgments The authors duly acknowledge the contributions of the Department of Biotechnology Engineering, International Islamic University Malaysia, for providing all the basic laboratory facilities to accomplish the research work. The authors also wish to thank Mr. Mutiu Kolade Amosa for his valuable assistance in the editing of this manuscript.

\section{References}

Acar FN, Eren Z (2006) Removal of $\mathrm{Cu}(\mathrm{II})$ ions by activated poplar sawdust (Samsun Clone) from aqueous solutions. J Hazard Mater B 137:909-914

Ahmad AL, Ismail S, Bhatia S (2003) Water recycling from palm oil mill effluent (POME) using membrane technology. Desalination 157:87-95

Alam MdZ, Muyibi SA, Mansor MF, Wahid R (2006) Removal of phenol by activated carbons prepared from palm oil mill effluent sludge. J Environ Sci 18(3):446-452

Ali I (2013) The quest for active carbon adsorbent substitutes, inexpensive adsorbents for toxic metal ions removal from wastewater. Sep Purif Rev 39:95-171

Ali I, Asim M, Khan TA (2012) Low cost adsorbents for the removal of organic pollutants from wastewater. J Environ Manag 113: $170-183$
Alkhatib MF, Muyibi SA, Amode JO (2011) Optimization of activated carbon production from empty fruit bunch fibers in one-step steam pyrolysis for cadmium removal from aqueous solution. Environmentalist 31:349-357

Baseri JR, Palanisamy PN, Sivakumar P (2012) Comparative studies of the adsorption of direct dye on activated carbon and conducting polymer composite. E-J Chem 9(3):1122-1134

Bello MM, Nourouzi MM, Chuah Abdullah L, Choong TSY, Koay YS, Keshani S (2013) POME is treated for removal of color from biologically treated POME in fixed bed column: applying wavelet neural network (WNN). J Hazard Mater 262(15):106-113

Borja R, Banks CJ (1994) Anaerobic digestion of palm oil mill effluent using up-flow anaerobic sludge blanket reactor. Biomass Bioenergy 6:381-389

Bousher A, Shen X, Edyvean RGJ (1997) Removal of coloured organic matter by adsorption onto low-cost waste materials. Water Res 31:2084-2092

Divya N, Bansal A, Jana AK (2013) Photocatalytic degradation of azo dye Orange II in aqueous solutions using copper-impregnated titania. Int J Environ Sci Technol. doi:10.1007/s13762-013-0238-8

Gupta VK, Mittal A, Krishman L, Mittal J (2006) Adsorption treatment and recovery of the hazardous dye, brilliant blue FCF, over bottom ash and de-oiled soya. J Colloid Interface Sci 293:16-26

Gupta VK, Jain R, Varshney S (2007) Removal of Reactofix golden 3 RFN from aqueous solution using wheat husk-an agricultural waste. J Hazard Mater 142:443-448

Gupta VK, Mittal A, Malviya A, Mittal J (2009) Adsorption of carmoisine A from wastewater using waste materials-bottom ash and deoiled soya. J Colloid Interface Sci 335:24-33

Gupta VK, Agarwal S, Saleh TA (2011) Chromium removal by combining the magnetic properties of iron oxide with adsorption properties of carbon nanotubes. Water Res 45:2207-2212

Karthikeyan S, Gupta VK, Boopathy R, Titus A, Sekaran G (2012) A new approach for the degradation of high concentration of aromatic amine by heterocatalytic Fenton oxidation: kinetic and spectroscopic studies. J Mol Liq 173:153-163

Leon y Leon CA, Solar JM, Calemma V, Radovic LR (1992) Evidence for the protonation of basal plane sites on carbon. Carbon 30:797-811

Lin SH, Lo CC (1996) Treatment of textile wastewater by foam flotation. Environ Technol 17:841-849

Lopez-Grimau V, Gutierrez MC (2006) Decolourisation of simulated reactive dyebath effluents by electrochemical oxidation assisted by UV light. Chemosphere 62:106-112

Mall ID, Srivastava VC, Agarwal NK, Mishra IM (2005) Removal of congo red from aqueous solution by bagasse fly ash and activated carbon: kinetic study and equilibrium isotherm analyses. Chemosphere 61:492-501

McClung SM, Lemley AT (1994) Electrochemical treatment and HPLC analysis of wastewater containing acid dyes. Text Chem Color 26:17-22

Mittal A, Gupta VK, Malviya A, Mittal J (2008) Process development for the batch removal and recovery of a hazardous, water-soluble azo dye (metanil yellow) by adsorption over waste materials (bottom ash and de-oiled soya). J Hazard Mater 151:821-832

Mittal A, Mittal J, Malviya A, Kaur D, Gupta VK (2010) Adsorption of hazardous dye crystal violet from wastewater by waste materials. J Colloid Interface Sci 343:463-473

Mohammed RR (2013) Decolorisation of biologically treated palm oil mill effluent (POME) using adsorption technique. Int Refer $\mathbf{J}$ Eng Sci 2(10):01-11

Namasivayam C, Dinesh KM, Selvi K, Ashruffunissa BR, Vanathi T, Yamuna RT (2001a) Waste coir pith-a potential biomass for the treatment of dyeing wastewaters. Biomass Bioenergy 21:477-483 
Namasivayam C, Radhika R, Suba S (2001b) Uptake of dyes by a promising locally available agricultural solid waste: coir pith. Waste Manage 21:381-387

Ncibi MC, Mahjoub B, Seffen M (2007) Adsorptive removal of textile reactive dye using Posidonia oceanica (L.) fibrous biomass. Int J Environ Sci Technol 4(4):433-440

Oakes J, Gratton P (1998) Kinetic investigations of the oxidation of arylazonaphthol dyes in hypochlorite solutions as a function of pH. J Chem Soc Perkin Trans 2(10):2201-2206

Özer A, Gürbüz G, Calimli A, Körbahti BK (2009) Biosorption of copper (II) ions on Enteromorpha prolifera: application of response surface methodology (RSM). Chem Eng J 146:377-387

Pala A, Tokat E (2002) Colour removal from cotton textile industry wastewater in an activated sludge system with various additives. Water Res 36:2920-2925

Papic S, Koprivanac N, LoncaricBozic A (2000) Removal of reactive dyes from wastewater using Fe(III) coagulant. J Soc Dyers Colour 116:352-358

Poulios I, Aetopoulou I (1999) Photocatalytic degradation of the textile dye reactive orange 16 in the presence of $\mathrm{TiO}_{2}$ suspensions. Environ Technol 20:479-487
Sanghavi BJ, Srivastava AK (2010) Simultaneous voltammetric determination of acetaminophen, aspirin and caffeine using an in situ surfactant-modified multiwalled carbon nanotube paste electrode. Electrochim Acta 55:8038-8048

Sanghavi BJ, Mobin SM, Mathur P, Lahiri GK, Srivastava AK (2013) Biomimetic sensor for certain catecholamines employing copper(II) complex and silver nanoparticle modified glassy carbon paste electrode. Biosens Bioelectron 39:124-132

Toor M, Jin B (2012) Adsorption characteristics, isotherm, kinetics, and diffusion of modified natural bentonite for removing diazo dye. Chem Eng J 187(1):79-88

Velmurugan P, Rathina KV, Dhinakaran G (2011) Dye removal from aqueous solution using low cost adsorbent. Int J Environ Sci 1(7):1492-1503

Yusoff I (2006) Renewable energy from palm oil-innovation on effective utilization of waste. J Clean Prod 14:87-93

Zahrim AY, Rachel FM, Menaka S, Su SY, Melvin F, Chan ES (2009) Decolourisation of anaerobic palm oil mill effluent via activated sludge-granular activated carbon. World Appl Sci J 5:126-129 